\title{
DEVELOPMENT OF CONDUCTING COPOL YMER BASED ON POLY (o-TOLUIDINE-co-2-AMINO 5 NAPTHOL 7 SULPHONIC ACID): AN EFFICIENT MATERIAL FOR PROTECTION OF IRON IN HIGHLY CORROSIVE ENVIRONMENT
}

\author{
Brij Mohan Singh Bisht ${ }^{1,3,4}$, Hema Bhandari ${ }^{2}$, S.P.Gairola ${ }^{3}$, Sundeep K Dhawan ${ }^{4}$ \\ ${ }^{1}$ Scientific Officer, Chemical Division, National Test House Ghaziabad (U.P.), India \\ ${ }^{2}$ Assistant Professor, Chemistry Department of, Maitreyi College, University of Delhi, India \\ ${ }^{3}$ Associate Professor, Physics Department Uttaranchal University Dehradun (Uttarakhand), India \\ ${ }^{4}$ Chief Scientist, Polymeric \& Soft Materials Section, CSIR-National Physical Laboratory, New Delhi, India
}

\begin{abstract}
The paper reports the corrosion inhibition performance of highly soluble conducting copolymer based on Poly(o-Toluidine-co-2Amino-5-Naphthol-7-Sulphonic Acid). The copolymer was synthesized by in situ chemical oxidative polymerization method by taking different molar concentration of comonomers. Characterization of synthesized copolymer was carried out by using FTIR, TGA and SEM measurement. The corrosion inhibition behaviour of the copolymer in $1.0 \mathrm{M} \mathrm{HCl}$ has been evaluated using Tafel Extrapolation method, electrochemical impedance spectroscopy (EIS) and weight loss measurements. The results showed that the copolymer consists of higher concentration of naphthyl amine comonomer exhibited the significant shifting in the corrosion potential and greater charge transfer resistance in highly aggressive medium such as $1.0 \mathrm{M} \mathrm{HCl}$. Maximum corrosion inhibition efficiency up to $95 \%$ was obtained at 200 ppm concentration of the inhibitor. Moreover, the copolymer showed the larger degree of surface coverage onto the iron surface exhibits least corrosion rate, indicating the better protection of the iron in highly acidic medium.
\end{abstract}

Keywords: Conducting Copolymer, Corrosion Inhibitors, Tafel Plots, Impedance Spectroscopy.

\section{INTRODUCTION}

Metals such as iron and steel are widely used as the constructional material in most of the major industries mainly in power plant, chemical plants, food, petroleum, electrochemical industries water and oil pipelines etc due to their outstanding mechanical properties and low cost. The major problem of these metals is their dissolution/degradation in acidic, aqueous and alkaline medium. Corrosion of iron and steel in acidic aqueous solutions is one of the major areas of concern for many industries where acids are extensively used for various applications such as acid cleaning, acid pickling, descaling, and oil well acidizing. Due to the corrosive nature of the acid solution, the materials of manufacture are being corroded easily. Therefore, it is very important to introduce such inhibitors which can prevent the metals from dissolution and degradation, and also reduce acid consumption [1-3]. Among the several methods of corrosion protection such as cathodic protection [1,2], anodic protection [3] and coating [4], the use of chemical inhibitors is found to be the most efficient method for protection of metals from corrosion. A corrosion inhibitor is a chemical additive which when added to a corrosive aqueous environment reduces the rate of metal dissolution. Use of acid inhibitors such as organic compounds including sulfur, nitrogen and oxygen atoms is well known method for corrosion protection. The inhibiting action applied by organic compounds on the dissolution of metallic species is related to interactions by adsorption between the inhibitors and the metal surface [4-7]. High electron density of the heteroatom such as nitrogen and sulphur atoms present in hetero compounds facilitates the organic molecule to get adsorbed onto the metal surface [7].

Moreover, the high-quality inhibitors should have the properties like cost effective, high inhibition efficiency, low toxicity and easy production and better solubility in common organic solvents $[6,7]$.

Conducting polymers such as polyaniline, polypyrrole and their copolymers found to be highly efficient inhibitors for protection of metal from corrosion due to presence of $\pi$ electrons, quaternary nitrogen atom and large molecular size [8-10].

In the last two decades; conducting polymer based inhibitors has been playing an important role to inhibit the corrosion of steel in highly corrosive conditions [3-7]. Among all conducting polymers, polyaniline has a special representation due to easy synthesis, environmental stability, simple non-redox doping by protonoic acids. Though, the commercial utilization of most of the applications based on polyaniline is very much related to the ease of its 
processability and solubility. Solubility of polyaniline in common organic solvents like ethanol, methanol or water is the most important requirement for its use as a corrosion inhibitor; however polyaniline is insoluble in these solvents. On the basis of literature it was found that the use of alkylsubstituted polyaniline and their copolymers, better solubility in organic solvents like ethanol and methanol can easily be achieved because of the stereo-electronic effects of the substituent on the torsion angle [11-13]. Bhandari et al reported corrosion inhibition behavior of poly(aniline-co-2isopropylaniline), on the basis of literature, it was observed that copolymers based on aniline and alkyl substituted aniline were found to be better corrosion inhibitors as compared to polyaniline [5]. In addition, Bhandari et al also reported the corrosion inhibitor behavior of conducting copolymer based on poly(Aniline-co-1-amino-2-naphthol-4sulfonic acid). Copolymers based on naphthyl amine derivatives bearing different functional group like $-\mathrm{OH}$, $\mathrm{NH}_{2}$ were found to be highly efficient corrosion inhibitors in strong acidic medium $[14,15]$.

Therefore, the present work deals with the development and evaluation of highly soluble conducting copolymer based on Poly(o-Toluidine-co-2-Amino-5-Naphthol-7-Sulphonic acid) for protection of iron in highly corrosive acid medium (i.e.1.0 M HCl). To the best of our knowledge, there was no report in the literature related to the corrosion inhibition behavior of conducting copolymer based on Poly(oToluidine-co-2-Amino-5-Naphthol-7-Sulphonic acid). The corrosion inhibition behavior of synthesized copolymer was evaluated using Tafel weight loss method, polarization and electrochemical impedance spectroscopy (EIS) measurements.

\section{EXPERIMENTAL}

\subsection{Materials}

Ortho-toluidine (OT) and 2-Amino-5-Naphthol-7-Sulphonic acid (ANS) (Loba Chemie, India) was used after distillation. Ammonium peroxydisulphate (APS) (Merck, India) and pToluene sulphonic acid (PTSA) were purchased from Aldrich, India. Aqueous solutions were prepared from the double distilled water having specific resistivity of $1 \mathrm{M} \Omega$ $\mathrm{cm}$.

\subsection{Synthesis of Poly (o-Toluidine-co-2-Amino-5-}

\section{Naphthol-7-Sulphonic Acid)}

Conducting copolymer Poly(o-Toluidine-co-2-Amino-5Naphthol-7-Sulphonic acid) have been synthesised by chemical oxidative polymerization using p-Toluene sulphonic acid (PTSA) as a dopant. For preparation of Poly(o-Toluidine-co-2-Amino-5-Naphthol-7-Sulphonic acid), different molar ratio of comonomers such as $(0.1 \mathrm{M} \mathrm{o-}$ Toluidine and $0.01 \mathrm{M}$ 2-Amino-5-Naphthol-7-Sulphonic acid) and (0.1 M o-Toluidine and $0.1 \mathrm{M}$ 2-Amino-5Naphthol-7-Sulphonic acid) was taken in $0.2 \mathrm{M}$ PTSA solution The copolymerization was initiated by the drop wise addition of aqueous solution of $0.1 \mathrm{M}$ ammonium peroxydisulfate (APS) which acts as an oxidant. The copolymerization was carried out at a temperature of $0-3{ }^{\circ} \mathrm{C}$ for a period of 4-6 h. The synthesized copolymers was isolated from reaction mixture by filtration and washed with distilled water to remove oxidant and oligomers and followed by drying in the vacuum oven at $60^{\circ} \mathrm{C}$. Synthesised Poly(o-Toluidine-co-2-Amino-5-Naphthol-7-Sulphonic acid) having different molar ratio of comomers $(0.1 \mathrm{M}$ oToluidine and $0.01 \mathrm{M}$ 2-Amino-5-Naphthol-7-Sulphonic acid) and $(0.1 \mathrm{M}$ o-Toluidine and $0.1 \mathrm{M}$ 2-Amino-5Naphthol-7-Sulphonic acid) was designated as POT-coANS1 and POT-co-ANS2 respectively.

\section{CHARACTERIZATION}

The structure of the copolymer was characterized by Fourier Transform Tnfrared (FTIR) Spectrometer (Nicolet 5700 FTIR, USA) in $\mathrm{KBr}$ pellets in the range of $400-4000 \mathrm{~cm}^{-1}$. TGA (Mettler Toledo TGA/SDTA 851e, Switzerland) was used to investigate the thermal stability of copolymers in nitrogen atmosphere. A heating rate of $10^{\circ} \mathrm{C} / \mathrm{min}$ and a sample size (in the form of fine powder) of $10 \pm 2 \mathrm{mg}$ were used in each experiment. Morphology was observed using Scanning Electron Microscopy (SEM; Leo S-440, Germany).

\subsection{Study of the Corrosion- Inhibition Performance}

\section{of Inhibitors}

The corrosion inhibition study was carried out at room temperature in aqueous solution of $1.0 \mathrm{M} \mathrm{HCl}$ by using electrochemical impedance spectroscopy measurements and potentiodynamic polarization technique. Experiments were carried out in a usual three electrode cell system using Autolab Potentiostat/ Galvanostat, PGSTAT100 (Nova Software). Pure mild steel of dimension $1 \mathrm{~cm} \mathrm{x} 1 \mathrm{~cm}$ was employed as working electrode embedded in araldite epoxy, Platinum as counter electrode and saturated calomel electrode (SCE) as reference electrode. The cleaning of the working iron electrode was carried out by fine emery papers and then the mild steel electrodes were thoroughly cleaned with trichloroethylene and acetone to remove the extra impurities from the metal surface. The linear Tafel segments to the anodic and cathodic curves $(-0.2$ to $+0.2 \mathrm{~V}$ versus corrosion potential) were extrapolated to corrosion potential to obtain the corrosion current densities. The corrosion current density $\left[i_{\text {corr }}\left(\mathrm{A} / \mathrm{cm}^{2}\right)\right]$ was calculated with the SternGeary equation [16]. The corrosion inhibition efficiency (\% I.E.) was determined from the measured $i_{\text {corr }}$ (corrosion current densities without addition of inhibitor $\left(\mathrm{i}_{\text {corr }}\right)$ and corrosion current densities with the addition of various concentrations of inhibitor $\left(\mathrm{i}_{\text {corr }}^{\mathrm{i}}\right)$ values by using the following relationship;

$$
\text { I.E. }(\%)=\frac{i_{\text {corr }}^{0}-i_{\text {corr }}^{i}}{i_{\text {corr }}^{0}} \times 100
$$

The corrosion inhibition efficiency was also calculated by measured charge transfer resistance $R_{c t}$ value in electrochemical impedance study (EIS), using Frequency Response Analyser (FRA) 2.3 where AC signals of $10 \mathrm{mV}$ 
amplitude and a frequency spectrum from $10 \mathrm{KHz}$ to $10 \mathrm{~Hz}$ were applied. In impedance studies, the corrosion inhibition efficiency was calculated by measured charge transfer resistance $\mathrm{R}_{\mathrm{ct}}$ value with following relationship;

$$
\text { I.E. }(\%)=\frac{R_{c t}^{i}-R_{c t}^{0}}{R_{c t}^{i}} \times 100
$$

where, $\mathrm{R}_{\text {ct }}^{0}$ and $\mathrm{R}_{\mathrm{ct}}^{\mathrm{i}}$ are the charge transfer resistance in the absence and in presence of inhibitors respectively. The Nyquist plots obtained by impedance measurements showed single semicircle curves which indicate the occurrence of a single charge transfer reaction. The curves show the depressed semicircle indicating the activation controlled nature of the reaction process with micro roughness at the surface of iron electrode during corrosion [17]. The impedance data were analysed with the equivalent circuit as shown in the Fig. 1,

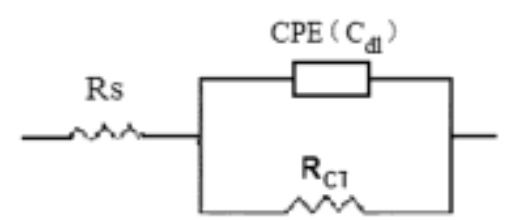

Fig-1: Electrical Equivalent circuit of EIS

where $R_{c t}$ is the charge transfer resistance, $R_{s}$ is the solution resistance and CPE is the constant phase element of double layer capacitance $\left(\mathrm{C}_{\mathrm{dl}}\right)$. The $\mathrm{C}_{\mathrm{dl}}$ has been estimated from the impedance value of the frequency $\left(f_{\max }\right)$ having maximum imaginary component with Nyquist plot by using following relationship [18];

$$
C_{d l}=\frac{1}{2 \pi f_{\max } R_{c t}}
$$

and the surface coverage $(\theta)$ by the inhibitor molecule can be calculated by using the following relationship;

$$
\theta=\frac{C_{d l}^{0}-C_{d l}^{i}}{C_{d l}^{0}}
$$

where $\mathrm{C}_{\mathrm{dl}}^{0}$ and $\mathrm{C}_{\mathrm{dl}}^{\mathrm{i}}$ are the double layer capacitance in the absence and in presence of inhibitors respectively.

\subsection{Weight Loss Method}

The weight loss methods have also been performed for corrosion study. The iron specimens of dimension $4 \times 3 \mathrm{~cm}^{2}$ were weighed in an electronic balance with an accuracy of $0.1 \mathrm{mg}$. before immersion in $\mathrm{HCl}$ medium. Iron specimens have been tested for same span of time by immersing the samples in aqueous solution of $1.0 \mathrm{M} \mathrm{HCl}$ with and without addition of inhibitors after 20 days. After 20 days of immersion specimens were removed from the tested solution, washed thoroughly with distilled water followed by acetone and dried with air, then weighed again. The corrosion inhibition performance was checked visually and using calculation of the weight loss. Weight loss is expressed as the loss in the weight per unit area or per unit area per unit time $\left(\mathrm{g} \mathrm{cm}^{-2} \mathrm{~h}^{-1}\right)$ as follows:

$W L=\frac{w_{0}-w_{1}}{a . t}$

where, $\mathrm{w}_{0}=$ initial weight of the sample before immersion $(\mathrm{g}) ; \mathrm{w}_{1}=$ weight of the sample after immersion $(\mathrm{mg}) ; \mathrm{a}=$ surface area $\left(\mathrm{cm}^{2}\right)$ of specimen; $\mathrm{t}=$ end time $(\mathrm{h})$ of each experiment.

\section{RESULTS AND DISCUSSION}

\subsection{FTIR Spectra}

Fig. 2 shows the FTIR spectra of POT-co-ANS, band around $815-820 \mathrm{~cm}^{-1}$ is due to the out of the plane $\mathrm{C}-\mathrm{H}$ bending vibrations and is indicative of the para coupling i.e. the polymerization occurs at 1-4 position in o-toluidine ring. The band around $757 \mathrm{~cm}^{-1}$ and $750 \mathrm{~cm}^{-1}$ is due to the out-ofplane $-\mathrm{CH}-$ bending of $1,2,4$-trisubstituted ring due to otoluidine ring in copolymer chain. The band at $1040 \mathrm{~cm}^{-1}$ in corresponds to $\mathrm{S}=\mathrm{O}$ stretching mode of the $-\mathrm{SO}_{3}$ group of PTSA. Copolymer of OT and ANS also showed a characteristic band at $1350 \mathrm{~cm}^{-1}$, due to presence $-\mathrm{OH}$ in plane bending, characteristic band at $3234 \mathrm{~cm}^{-1}$ is due to hydrogen bonded $-\mathrm{OH}$ and $-\mathrm{NH}_{2}$ groups.

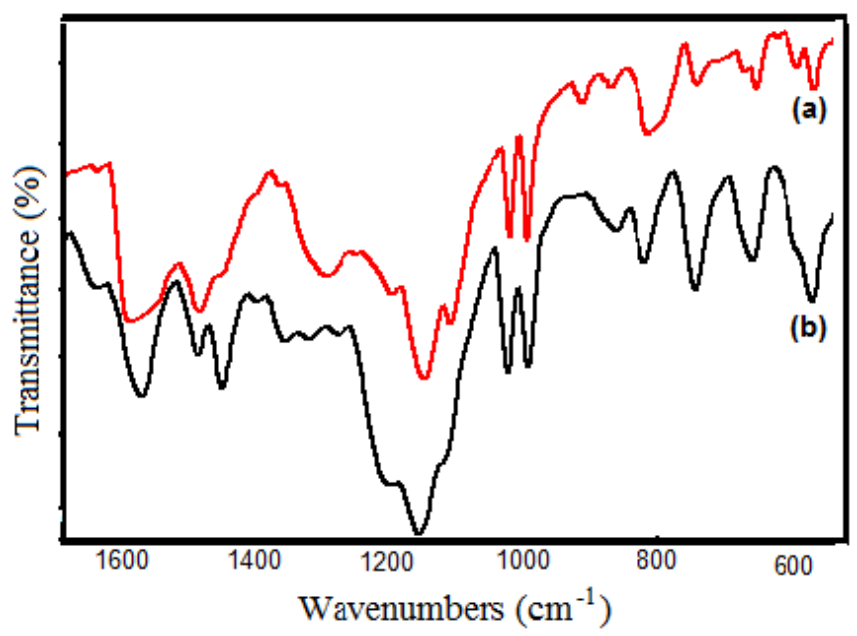

Fig-2: FTIR spectra of (a) POT-co-ANS1 and (b) POT-coANS2

A strong band at around $845 \mathrm{~cm}^{-1}$ was observed in FTIR spectra of copolymer due to the $\mathrm{C}-\mathrm{H}$ bending vibration of tetra substituted benzene ring which indicates that the both fused benzene ring in naphthalene structure of ANS unit is tetra substituted and it further reveals that the forth position of ANS unit bonded o-toluidine molecule during copolymerization. Possible structure of copolymer based on o-toluidine and 2-amino-5-naphthol-7-sulphonic acid is given in Fig.3. 


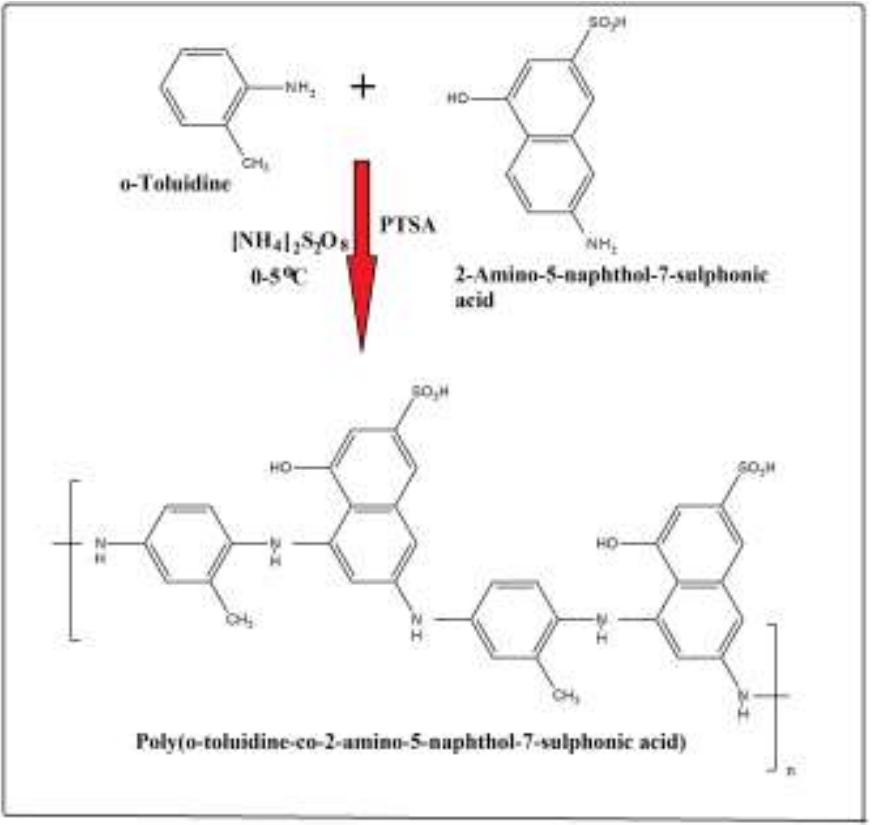

Fig-3: Schematic diagram for formation of POT-co-ANS copolymer

\subsection{Thermo Gravimetric Analysis}

Fig. 4 shows the thermo-gravimetric curves (TGA) of POTco-ANS. The sample was heated from 25 to $700^{\circ} \mathrm{C}$ under a constant heating rate of $10^{\circ} \mathrm{C} / \mathrm{min}$ and inert atmosphere of nitrogen gas.

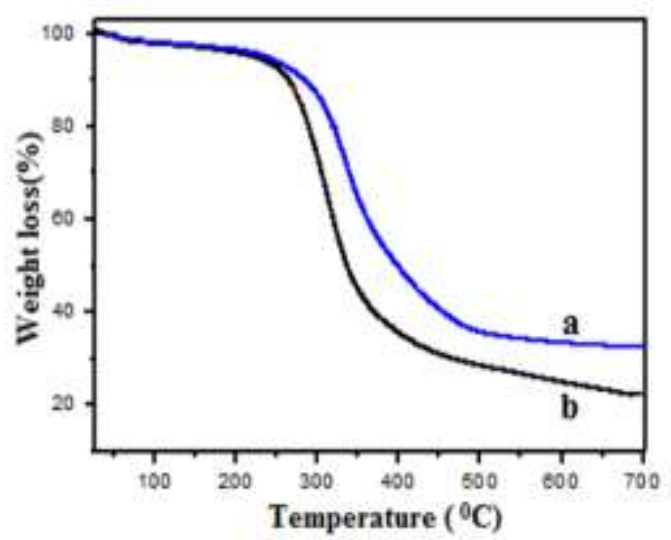

Fig-4: TGA curves of (a) POT-co-ANS1 and (b) POT-coANS2

It was observed that conducting copolymers POT-co-ANS1 and POT-co-ANS2 showed an excellent thermal stability in the range of 250 to $270^{\circ} \mathrm{C}$. The TGA curve of copolymer indicates that first weight loss at $100-110^{\circ} \mathrm{C}$ is attributed to the loss of water and other volatile species. The weight loss in the second step at about $250-270^{\circ} \mathrm{C}$ onwards involves the loss of dopant ions as well as onset of degradation of copolymer backbone.

\subsection{Morphological Characterization of Copolymers}

Fig.5 shows the scanning electron microscopy (SEM) images of copolymers (POT-co-ANS1 and POT-co-ANS2). SEM image of copolymer consists of $0.1 \mathrm{M}$ OT and $0.01 \mathrm{M}$
ANS showed rock like morphology. On increasing the molar concentration of ANS comonomer, change the morphology of copolymer (POT-co-ANS2) to tubular shape as shown in Fig.5, which indicates that the tube like shape of the copolymer is due the incorporation of higher concentration ANS in copolymer matrix.

\subsection{Solubility}

On the basis of literature it was observed that polyaniline doped with dopant such as inorganic protonic acid like $\mathrm{HCl}$ is found to be slightly insoluble in organic solvents. However, polyaniline doped with organic aromatic sulphonic acid dopants like p-toluene sulphonic acid and Dodecyl benzene sulphonic acid is soluble in chloroform, DMF, DMSO but rather insoluble in common organic solvents like water and alcohols [19].
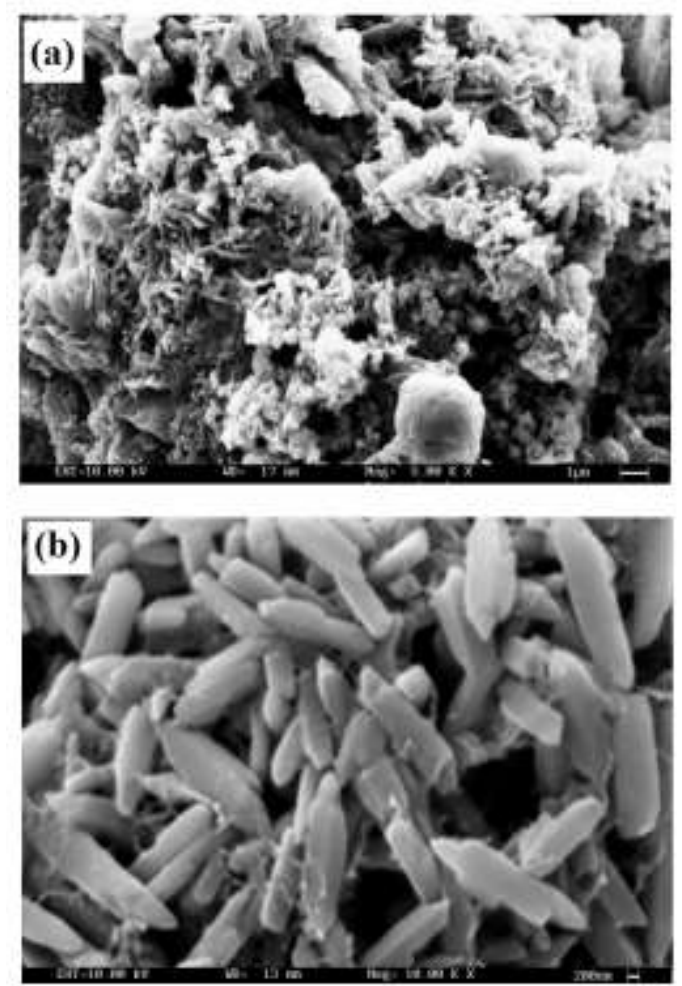

Fig-5 SEM images of (a) POT-co-ANS1 and (b) POT-coANS2

On the other hand it was found that the copolymers based POT-co-ANS doped with PTSA was found to be soluble in common organic solvents such as methanol and ethanol. Copolymers POT-co-ANS1 showed upto $60 \%$ and POT-coANS2 exhibited upto $90 \%$ solubility in alcohol. Solubility of synthesized copolymers is better than polyaniline due to the steric hindrance brought about by the introduction of different substituents at the aniline and naphthalene rings. Higher concentration of ANS monomer in copolymer chain also plays an important role to improve solubility of copolymer in organic solvents. For corrosion studies by electrochemical methods, the methanol medium was selected as a solvent for corrosion studies as all the corrosion studies for iron were carried out in aqueous solution of $1.0 \mathrm{M} \mathrm{HCl}$, since methanol is miscible with aqueous medium, it has not affected the overall performance of the corrosion inhibition studies. 


\section{CORROSION INHIBITION STUDY}

\subsection{Tafel Extrapolation Measurement}

Fig.6 shows the Tafel polarization curve for iron in $1.0 \mathrm{M}$ $\mathrm{HCl}$ with the addition of various concentrations of inhibitors (POT-co-ANS) in methanol. The copolymers were highly soluble in various organic solvents such as ethanol, methanol DMSO and NMP, but in the present studies, we have selected methanol as a solvent due to its good solubility in aqueous solution of $\mathrm{HCl}$.

Table-1: Tafel parameters for iron in $1.0 \mathrm{M} \mathrm{HCl}$ containing different concentration of inhibitors

\begin{tabular}{|l|l|l|l|l|}
\hline $\begin{array}{l}\text { Inhibitor's } \\
\text { name }\end{array}$ & $\begin{array}{l}\text { Inhibitor's } \\
\text { concentratio } \\
\mathrm{n}\end{array}$ & $\begin{array}{l}\mathrm{E}_{\text {corr }} \\
(\text { Volts })\end{array}$ & $\begin{array}{l}\mathrm{i}_{\text {corr }} \\
\left(\mu \mathrm{A} / \mathrm{cm}^{2}\right. \\
)\end{array}$ & $\begin{array}{l}\text { I.E } \\
(\%)\end{array}$ \\
\hline $\begin{array}{l}\text { Without } \\
\text { inhibitor }\end{array}$ & --- & -0.548 & 918 & -- \\
\hline POT-co- & 50 & -0.505 & 430 & 53 \\
ANS1 & 100 & -0.480 & 265 & 71 \\
& 150 & -0.460 & 206 & 76 \\
& 200 & -0.445 & 165 & 82 \\
\hline & 50 & -0.485 & 251 & 73 \\
POT-co- & 100 & -0.466 & 190 & 79 \\
ANS2 & 150 & -0.440 & 149 & 84 \\
& 200 & -0.421 & 50 & 95 \\
\hline
\end{tabular}
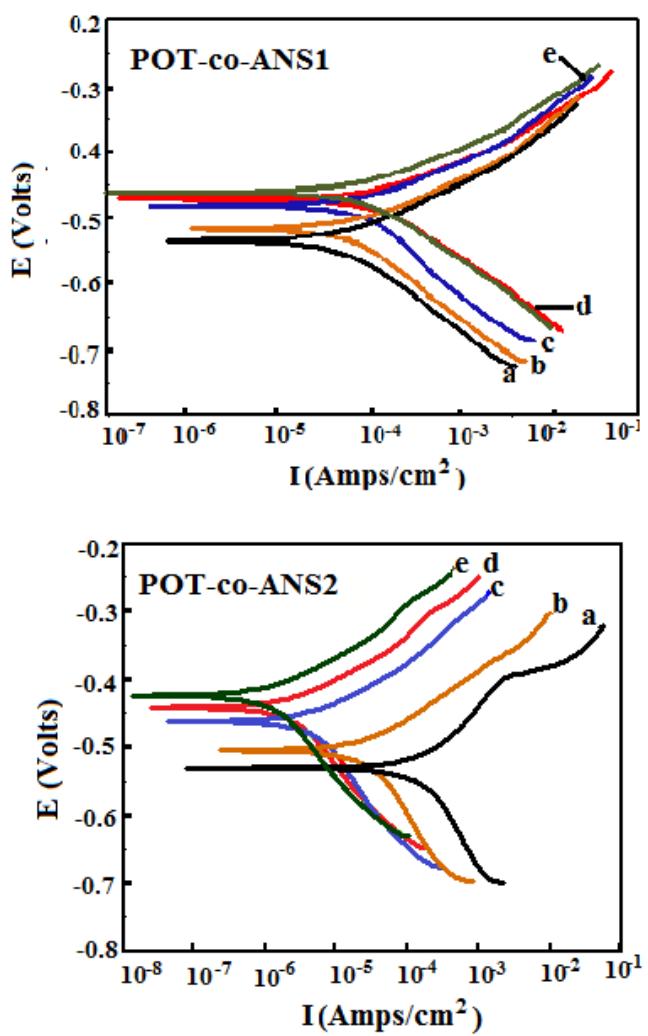

Fig-6: Tafel plots of copolymers in different concentration (a) without inhibitor, (b) $50 \mathrm{ppm}$, (c) $100 \mathrm{ppm}$, (d) $150 \mathrm{ppm}$ and (e) $200 \mathrm{ppm}$

The Tafel curves expose that the corrosion potential $\left(\mathrm{E}_{\mathrm{corr}}\right)$ value of iron in $1.0 \mathrm{M} \mathrm{HCl}$ was found to be $-0.548 \mathrm{~V}$ without addition of inhibitors. Addition of different concentration of inhibitors POT-co-ANS1 showed a remarkable potential shift from $-0.548 \mathrm{~V}$ to $-0.455 \mathrm{~V}$ versus SCE in the corrosion potential $\left(\mathrm{E}_{\text {corr }}\right)$, relative to the value of the iron without inhibitors. The positive shift in $E_{\text {corr }}$ indicates the significant inhibition performance of iron in presence of inhibitor in acidic medium. Moreover, corrosion current density $\left(\mathrm{i}_{\text {corr }}\right)$ value of the iron electrode was also reduced significantly by using POT-co-ANS1 inhibitor. The corrosion kinetic parameters derived from these curves are given in the Table 1. It is clear from the Table 1 , that the corrosion current density $\left(\mathrm{i}_{\text {corr }}\right)$ decreased from $918 \mu \mathrm{A} / \mathrm{cm}^{2}$ iron electrode (without inhibitor) to $265 \mu \mathrm{A} / \mathrm{cm}^{2}$ with the addition of $100 \mathrm{ppm}$ concentration of POT-co-ANS1 copolymer. On increasing the concentration of POT-coANS1 at $200 \mathrm{ppm}$ in acidic medium, the $\mathrm{i}_{\text {corr }}$ value decreased to $165 \mu \mathrm{A} / \mathrm{cm}^{2}$. Hence the addition of $200 \mathrm{ppm}$ concentration of copolymer based on $0.1 \mathrm{M}$ OT and $0.01 \mathrm{M}$ ANS, the $i_{\text {corr }}$ value decreased from $918 \mu \mathrm{A} / \mathrm{cm}^{2}$ for inhibitor-free solution to $165 \mu \mathrm{A} / \mathrm{cm}^{2}$ to yield a $82 \%$ corrosion inhibition efficiency. While in copolymer based on $0.1 \mathrm{M}$ OT and $0.1 \mathrm{M}$ ANS (POT-co-ANS2), the $\mathrm{i}_{\text {corr }}$ value decreased from $918 \mu \mathrm{A} / \mathrm{cm}^{2}$ for inhibitor-free solution to 50 $\mu \mathrm{A} / \mathrm{cm}^{2}$ on addition of $200 \mathrm{ppm}$ concentration. Corrosion inhibition efficiency of iron on addition of $200 \mathrm{ppm}$ solution of POT-co-ANS2 was found to $95 \%$ as shown in Fig. 6. The copolymer composition based on POT-co-ANS2 showed better inhibition efficiency than that of copolymer POT-co-ANS1.

\subsection{Electrochemical Impedance Spectroscopy (EIS)}

The Nyquist representations of the impedance behaviour of iron in $1.0 \mathrm{M} \mathrm{HCl}$ with and without addition of various concentrations of inhibitors are shown in Fig.7. The existence of single semicircle showed the single charge transfer process during the dissolution of metal. It was observed that the addition of copolymers increases the value of charge transfer resistance $\left(\mathrm{R}_{\mathrm{ct}}\right)$ and reduces the interfacial double layer capacitance $\left(\mathrm{C}_{\mathrm{dl}}\right)$.
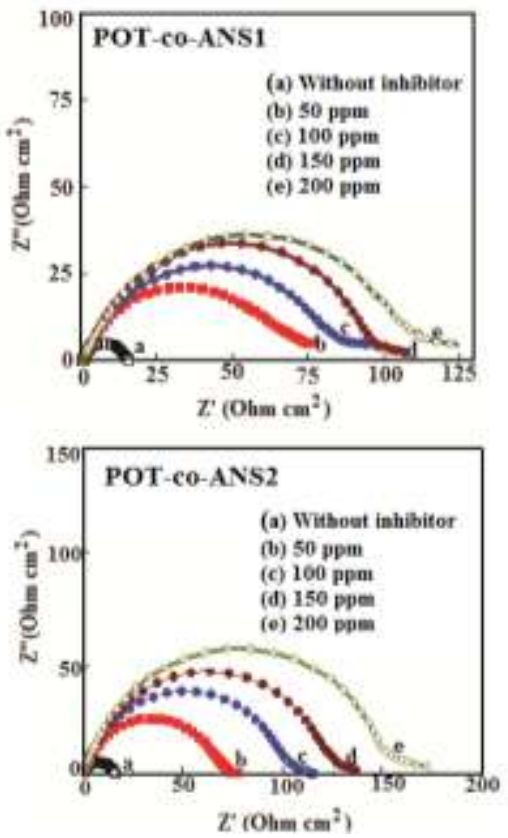

Fig-7: Nyquist Plots of copolymers in different concentrations 
The decrease in $\mathrm{C}_{\mathrm{dl}}$ value revealed the increase in thickness of electrical double layer. Moreover, the increase in $\mathrm{R}_{\mathrm{ct}}$ value is attributed to the formation of protective film on the metal/solution interface [20]. The $\mathrm{R}_{\mathrm{ct}}$ and $\mathrm{C}_{\mathrm{dl}}$ values derived from these curves are given in the Table 2. It is clear from the Table 2 that the charge transfer resistance $\left(\mathrm{R}_{\mathrm{ct}}\right)$ value of mild steel electrode increased from $12 \Omega \mathrm{cm}^{2}$ (without addition of inhibitor) to $78 \Omega \mathrm{cm}^{2}$ with the addition of 100 ppm concentration of POT-co-ANS1. Further addition of 200 ppm concentration of POT-co-ANS1, Rct value increased to $101 \Omega \mathrm{cm}^{2}$ as shown in Fig.7). While on increasing the concentration of copolymers POT-co-ANS2 (from $100 \mathrm{ppm}$ to $200 \mathrm{ppm}$ ), $\mathrm{R}_{\mathrm{ct}}$ value found to be increased from $100 \Omega \mathrm{cm}^{2}$ to $150 \Omega \mathrm{cm}^{2}$. The interfacial double layer capacitance $\left(\mathrm{C}_{\mathrm{dl}}\right)$ values derived from the Nyquist plot are given in the Table 2 .

Table-2: Electrochemical Impedance parameters for iron in $1.0 \mathrm{M} \mathrm{HCl}$ containing different concentration of inhibitors

\begin{tabular}{|l|l|l|l|l|}
\hline $\begin{array}{l}\text { Inhibitor's } \\
\text { Name }\end{array}$ & $\begin{array}{l}\text { Inhibitor's } \\
\text { concentratio } \\
\mathbf{n}\end{array}$ & $\begin{array}{l}\mathbf{R}_{\mathbf{c t}} \\
\left.\mathbf{( \Omega ~ c m}^{\mathbf{2}}\right)\end{array}$ & $\begin{array}{l}\mathbf{C}_{\mathbf{d l}} \\
(\boldsymbol{\mu} \mathbf{F c m}- \\
\mathbf{2})\end{array}$ & $\begin{array}{l}\mathbf{I . E} \\
(\boldsymbol{\%} \\
)\end{array}$ \\
\hline $\begin{array}{l}\text { Without } \\
\text { inhibitor }\end{array}$ & --- & 12 & 354 & -- \\
\hline POT-co- & 50 & 60 & 142 & 80 \\
ANS1 & 100 & 78 & 106 & 85 \\
& 150 & 95 & 92 & 87 \\
& 200 & 101 & 65 & 88 \\
\hline & 50 & 78 & 103 & 85 \\
POT-co- & 100 & 100 & 64 & 88 \\
ANS2 & 150 & 125 & 55 & 90 \\
& 200 & 150 & 37 & 92 \\
\hline
\end{tabular}

The $C_{\mathrm{dl}}$ values were found to decrease from $354 \mu \mathrm{F} \mathrm{cm}$ for inhibitor free solution to $142 \mu \mathrm{F} \mathrm{cm} \mathrm{cm}^{-2}, 106 \mu \mathrm{F} \mathrm{cm} \mathrm{cm}^{-2}, 92 \mu \mathrm{F}$ $\mathrm{cm}^{-2}$ and $65 \mu \mathrm{F} \mathrm{cm}$ with the addition of 50ppm, 100ppm, $150 \mathrm{ppm}$ and $200 \mathrm{ppm}$ concentration of POT-co-ANS1 respectively. While in case of POT-co-ANS2, $\mathrm{C}_{\mathrm{dl}}$ values were found to decrease from $354 \mu \mathrm{F} \mathrm{cm}$ for inhibitor free solution to $37 \mu \mathrm{F} \mathrm{cm} \mathrm{cm}^{-2}$ with the addition of $200 \mathrm{ppm}$ concentration. Moreover, the degrees of surface coverage of iron by these copolymers at different concentration of inhibitors have also been calculated, which revealed that copolymer prepared by using higher concentration of ANS i.e.0.1 M, showed the greater surface coverage onto the iron electrode. The large surface coverage upto $90 \%$ shown by POT-co-ANS2 at 200 ppm, indicates the greater adsorption of this inhibitor onto iron surface.

The mechanism of corrosion inhibition may be explained on the basis of adsorption behaviour [20, 21]. Fig. 8 shows the adsorption isotherms of POT-co-ANS2 copolymer. Data are tested graphically by fitting to various isotherms. A straight line was obtained on plotting the inhibitor concentration $C_{i n h}$ vs $\left(\mathrm{C}_{\mathrm{inh}} / \theta\right)$ for the copolymers. The linear relationship of the plots showed that these copolymers inhibited the corrosion of iron in acid solution i.e. $1.0 \mathrm{M} \mathrm{HCl}$ by surface coverage of inhibitor adsorption consistent with Langmuir adsorption isotherm.

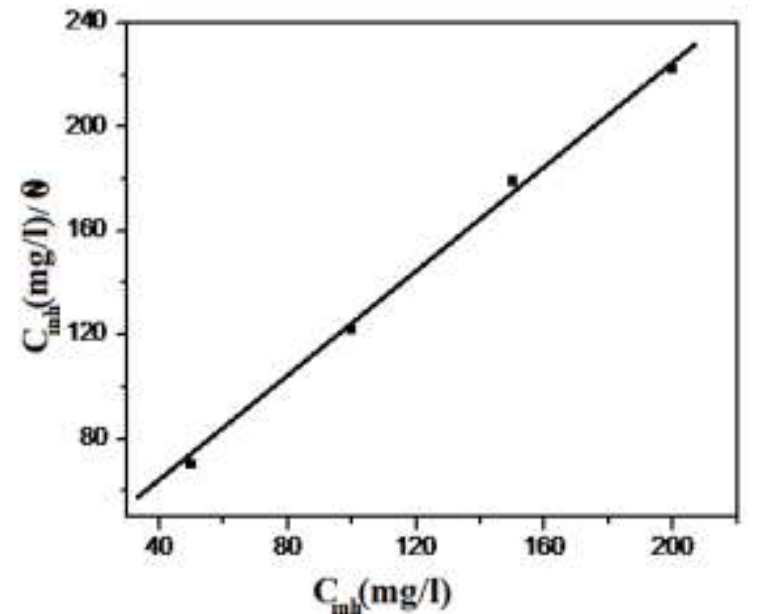

Fig-8: Langmuir adsorption isotherm plot for POT-coANS2 copolymer in $1.0 \mathrm{M} \mathrm{HCl}$, on the surface of iron.

\subsection{Weight Loss Measurements}

Table 3 shows the values of the weight loss from iron samples during the immersion test for 20 days in $1.0 \mathrm{M} \mathrm{HCl}$ solution. The results revealed that iron samples were more protectable in presence of POT-co-ANS2 inhibitors as compared to POT-co-ANS1 samples in same immersion time and same concentration.

Table -3: Weight loss study for iron in presence of inhibitors in $1.0 \mathrm{M} \mathrm{HCl}$

\begin{tabular}{|l|l|l|l|l|}
\hline $\begin{array}{l}\text { Inhibitor's } \\
\text { name }\end{array}$ & $\begin{array}{l}\text { Inhibitor } \\
\text { conc. } \\
(\mathrm{ppm})\end{array}$ & $\begin{array}{l}\text { Initial } \\
\text { Weight of } \\
\text { iron(mg) } \\
\text { before } \\
\text { immersion }\end{array}$ & $\begin{array}{l}\text { Final } \\
\text { weight } \\
\text { after } \\
\text { immersio } \\
\mathrm{n}(\mathrm{mg})\end{array}$ & $\begin{array}{l}\text { Weight } \\
\text { loss }(\%)\end{array}$ \\
\hline $\begin{array}{l}\text { Without } \\
\text { inhibitor }\end{array}$ & - & 32550.5 & 19520.2 & 40.00 \\
\hline \multirow{3}{*}{ POT-co-NS1 } & 50 & 32780.2 & 20560.6 & 37.27 \\
\cline { 2 - 5 } & 100 & 32798.9 & 25980.5 & 20.78 \\
\cline { 2 - 5 } & 150 & 34660.1 & 29500.6 & 14.88 \\
\cline { 2 - 5 } & 200 & 32560.0 & 28650.5 & 12.00 \\
\hline \multirow{3}{*}{ POT-co-NS1 } & 50 & 33462.0 & 25541.8 & 23.66 \\
\cline { 2 - 5 } & 100 & 32560.5 & 28335.2 & 12.97 \\
\cline { 2 - 5 } & 150 & 32930.0 & 29926.5 & 9.12 \\
\cline { 2 - 5 } & 200 & 33100.5 & 32202.0 & 2.71 \\
\hline
\end{tabular}

\subsection{Role of POT-co-ANS based Copolymer as}

\section{Corrosion Inhibitor}

It was found that the presence of amino naphthol sulphonic acid as a comonomer showed remarkable influence on the anticorrosive performance of the iron. The corrosion inhibition performance of iron increases with increasing the concentration of POT-co- ANS2 inhibitor from 50 to 200 ppm. Weight loss exhibited by iron samples in absence of inhibitor was $40 \%$. Iron samples showed the minimum weight loss i.e. $2.71 \%$ in presence of inhibitor (POT-coANS2) at $200 \mathrm{ppm}$ concentration of. 
The corrosion inhibition efficiency of the conducting copolymers of OT and ANS mainly depends on the pielectron conjugation, molecular size, quaternary nitrogen atom and their solubility. Use of polyaniline for corrosion inhibition of iron in acidic medium is restricted due to its insolubility in common organic solvents like methanol and ethanol. To overcome this problem, the copolymers of substituted aniline such as o-toluidine based inhibitor were selected for protection of iron in corrosive medium. Corrosion inhibition of iron in acidic environment by copolymer can be explained on the basis of molecular adsorption. The electrochemical impedance studies showed that these copolymers protect the iron from corrosion in aggressive medium through adsorption mechanism. availability of lone pair of electrons on the hetro atoms present in comonomer units support the copolymers to exhibit effective corrosion inhibition and greater coverage on the metal surface in acidic medium. Moreover, different functional groups present in naphthylamine ring such as $\mathrm{NH}_{2},-\mathrm{OH}$ and $-\mathrm{SO}_{3} \mathrm{H}$ also responsible for enhancing the corrosion inhibition performance of iron in acidic medium. In acidic solution, amines act as a cation and adsorb onto metal surface through electrostatic interaction between the positively charged anilinium cations hence adsorbed chloride ions [22]. Copolymer consists of OT and ANS act as a protonated species in acidic media which adsorb onto the surface of the iron to form a monomolecular barrier. As with barrier coatings, the adsorbed molecules restrict the anodic or cathodic corrosion reaction by reducing the corrosion rate [22-24]. Presences of delocalized pi electrons on the copolymer chain form co-ordination type of bonds with the iron surface. Iron in acidic medium is negatively charged, the existence of quarternary ammonium nitrogen acts as an anchoring unit which makes the polymer chain attached to the surface. Furthermore, it is also presumed that the bulkiness of substitution in aromatic ring build a cluster network on iron surface anchored more strongly resulting in good coverage of surface and enhanced inhibition efficiency. Solubility of the copolymers in alcohol also play an important role to improve the corrosion inhibition efficiency of iron. Therefore copolymers based on OT and ANSA can effectively be employed as a efficient corrosion inhibitors. Better corrosion inhibition performance shown by POT-co-ANS2 as compared to POT-co-ANS1 is due to the higher concentration of ANS moieties in copolymer chain.

\section{CONCLUSION}

Highly soluble conducting copolymers based on o-toluidine and 2-amino-5-naphthol-7-sulphonic acid have been synthesized by chemical oxidative copolymerization method. Synthesized copolymers were characterized by FTIR, TGA and SEM characterization to evaluate the structural, thermal and morphological behavior. Tafel polarization studies, electrochemical impedance measurements and weight loss study were carried out to evaluate the inhibition efficiencies of the copolymers at different concentration. Corrosion inhibition efficiency of copolymers increased with increasing inhibitor concentration as well as the incorporation of higher concentration of ANS in copolymer matrix. Impedance measurement gives the Nyquist plot of iron in $1.0 \mathrm{M} \mathrm{HCl}$ with and without addition of copolymers from where corrosion kinetic parameters were derived. Corrosion inhibition efficiency was found to be $82 \%$ in case copolymer (POT-co-ANS1) which was increased up to $95 \%$ by using the copolymer (POT-co-ANS2) at $200 \mathrm{ppm}$ concentration. The electrochemical impedance of iron in acidic medium with addition of these inhibitors revealed that these copolymers reduce the rate of corrosion of iron metal through adsorption mechanism. These studies clearly reveal that the synthesized copolymer with higher concentration of ANS unit has excellent corrosion inhibition properties and it can be considered as a potential material for protection of iron in corrosive medium like.1.0 M $\mathrm{HCl}$ at low concentration.

\section{ACKNOWLEDGEMENT}

Authors are highly obliged to Shri Sher Singh Director National Test House Ghaziabad for his keen interest in the work. The authors are also thankful Dr. B.P.Singh, Punjab University Chandigarh for recording the SEM characterization of the samples.

\section{REFERENCES}

[1] S.K.Shukla, M.A.Quraishi, R. Prakash, Corros. Sci. 50 (2008) 2867-2872.

[2] H.Zhua, L.Zhonga, S.Xiaoa, F.Gan, Electrochim.Acta 49 (2004) 5161.

[3] A.M. Alsabagh, M.A.Migahed, H.S.Awad, Corros. Sci. 48 (2006) 813-828.

[4] S. Sathiyanarayanan, S. Syed Azim, G. Venkatachari, Synth. Met. 157 (2007) 205-213.

[5] H. Bhandari, S. Sathiyanarayana, V. Choudhary S.K.Dhawan, Journal of Applied Polymer Science, 111 (2008), 2328-2339.

[6] H. Bhandari, V.Choudhary, S.K.Dhawan," Polymers for Advanced Technologies 20(12), (2008), 1024-1034.

[7] Yagan, N. O. Pekmez, A. Yildiz, Progress in organic coatings 57 (2006) 314-318.

[8] G. Ruhi, H. Bhandari, S.K.Dhawan, Progress in organic coating, 77(9) (2014), 1484.

[9] P Sambyal, G Ruhi, H. Bhandari, S. K. Dhawan, Surface \& Coating Technology, 272 (2015) 129,

[10] A Kumar.S, H. Bhandari, S.K. Dhawan "Polymer International, 62 (2013), 1192-1201.

[11] A.Yagan, N. O.Pekmez, A.Yıldı, Corros.Sci. 49 (2007) 2905-2919.

[12] M. K. Rokovic, K. Kvastek , V. Horvat-Radosevic, Lj. Duic, Corros.Sci.49 (2007) 2567-2580.

[13] H.J. Choi, J.W. Kim, K. To, Synth. Met. 101 (1999), 697.

[14] H. Bhandari, V. Choudhary, S.K. Dhawan, Thin Solid Film, 519 (2010) 1031-1039.

[15] H.Bhandari, V. Choudhary, S.K. Dhawan, Synthetic Metals, 161 (2011), 753-762.

[16] M. Stern, A. Geary, Electrochemical polarization, J. Electrochem Soc.104 (1957) 56.

[17] P. A. Kilmartin, L. Trier, G. A.Wright, Synth. Met. 31 (2002) 99- 109. 
[18] D.W. DeBerry, J. Electrochem. Soc. 132 (1985) 1022.

[19] P. Zarras, N. Anderson, C. Webber, D.J. Irvin, J.A. Irvin, A. Guenthner, J.D. Stenger-Smith, Radiation Physics and Chemistry 68 (2003) 387-394.

[20] P.S. Rao, D.N. Sathyanarayana, Synth. Met. 138 (2003) 519.

[21] S. Sathiyanarayanan, S.K. Dhawan, D.C. Trivedi, K. Balakrishnan, Corros. Sci. 33 (1992) 1831.

[22] C.Jeyaprabha, S.Sathiyaanarayanan, K.L.N Phani, G. Venkatachari, Appl.Surf.Sci. 252 (2005) 966.

[23] C.Jeyaprabha, S. Sathiyanarayanan, G. Venkatachari, J. Appl.Polym.Sci.101 (2006) 2144.

[24] D.O.Flamini, S.B.Saidman, Corros. Sci.52 (2010) 229234.

\section{BIOGRAPHIES}

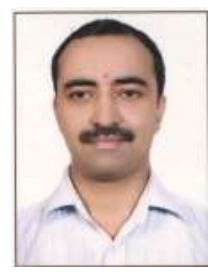

Mr. Brij Mohan Singh Bisht is working as Scientific Officer at National Test House, Ghaziabad. He is persuing his Ph.D. in the area of conducting polymers for Smart corrosion preventive coatings.

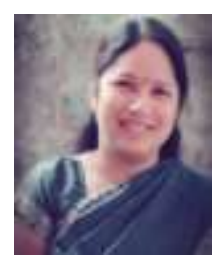

Dr. Hema Bhandari is working as Assistant Professor at Maitreyi College, University of Delhi. She did her Ph.D. in the area of "Designing of Conducting Polymers for Anticorrosive applications".

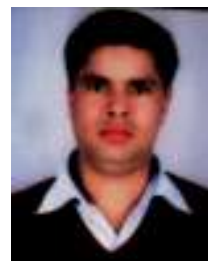

Dr. S.P. Gairola is working as Associate Professor in Uttranchal University. His research interests are in EMI shielding besides designing of materials for corrosion prevention.

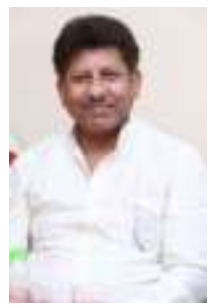

Dr. S.K. Dhawan, working as Chief Scientist at CSIR-National Physical Laboratory, New Delhi. His research interests are in the area of conducting polymers for exploring its applications in Smart coatings, waste plastic management and EMI Shielding. 